\title{
Çene Cerrahisi Doku Yara Tedavisinde Kullanılacak Bir Mikroşerit Anten Tasarımı
}

\author{
Zafer Emre Albayrak ${ }^{1}$, Çetin Kurnaz ${ }^{2 *}$ \\ 1 Ondokuz Mayıs Üniversitesi, Mühendislik Fakültesi, Elektrik-Elektronik Mühendisliği Bölümü, Samsun, Türkiye, (ORCID: 0000-0002-6632-1670), \\ zaferemre.albayrak@gmail.com \\ 2* Ondokuz Mayıs Üniversitesi, Mühendislik Fakültesi, Elektrik-Elektronik Mühendisliği Bölümü, Samsun, Türkiye (ORCID: 0000-0003-3436-899X), \\ ckurnaz@omu.edu.tr
}

(International Symposium on Multidisciplinary Studies and Innovative Technologies (ISMSIT) 2021 - 21-23 October 2021)

(DOI: $10.31590 /$ ejosat.1010456)

ATIF/REFERENCE: Albayrak, Z. E. \& Kurnaz, Ç. (2021). Çene Cerrahisi Doku Yara Tedavisinde Kullanılacak Bir Mikroşerit Anten Tasarımı. Avrupa Bilim ve Teknoloji Dergisi, (29), 111-116.

$\ddot{\mathbf{O z}}$

İnsan çene dokusunda yapılan cerrahi operasyonlar sonrasında doku bölgesinde oluşan yaraların tedavi süreçlerinin kısaltılması büyük önem taşımaktadır. Doku bölgesinde oluşan yaralar düşük frekanslı elektromanyetik dalgalara maruz bırakılarak iyileşme süreçleri kısaltılabilir. Bu çalışmada, çene cerrahisinde çene bölgesinde oluşan yara, ağrı ve ödem tedavisinde kullanılmak üzere CST programı kullanılarak bir anten düzeneği tasarlanmıştır. Anten düzeneği mikroşerit anten ve horn yansıtıcı olmak üzere iki kısımdan oluşmaktadır. Mikroşerit antenin çalışma frekansı elektromanyetik alan tedavileri ile doku iyileşmesinde olumlu sonuçlar veren 27 $\mathrm{MHz}$ seçilmiştir. Anten düzeneği ile elektromanyetik alanın sadece insan çene bölgesine ışıma yapması sağlanmıştır. Tasarlanan anten düzeneği ile oluşan elektrik alan ve manyetik alan değerleri ve bu değerler sonucunda çene bölgesinde oluşan SAR değerleri hesaplanmıştır.

\section{Design of a Microstrip Antenna to be Used in Maxillofacial Surgery Tissue Wound Treatment}

\begin{abstract}
It is of great importance to shorten the treatment processes of wounds formed in the tissue area after surgical operations on human jaw tissue. Healing processes can be shortened by exposing the wounds in the tissue area to low-frequency electromagnetic waves. In this study, an antenna assembly was designed using the CST program to be used in the treatment of wounds, pain and edema in the jaw area in maxillofacial surgery. Antenna assembly consists of two parts: microstrip antenna and horn reflector. $27 \mathrm{MHz}$ was chosen as the operating frequency of the microstrip antenna, which gives positive results in tissue healing with electromagnetic field treatments. With the antenna assembly, it is ensured that the electromagnetic field radiates only to the human chin area. The electric field and magnetic field values formed by the designed antenna assembly and the SAR values formed in the chin area as a result of these values were calculated.
\end{abstract}

Keywords: Microstrip antenna, Jaw tissue, Electromagnetic field therapy, CST.

\footnotetext{
*Sorumlu Yazar: ckurnaz@omu.edu.tr
} 


\section{Giriş}

Diş hekimliği cerrahi branşlarında insan çene bölgesine birçok farklı operasyon yapılmaktadır. $\mathrm{Bu}$ operasyonlar sonrasında çene bölgesinde oluşan doku yaralarının iyileşme sürelerinin kısaltılması; komplikasyonları önlemek, hastanın normal hayata dönüş süresi kısaltmak, tedavi başarı oranı arttırmak ve enfeksiyonları önlenmek adına büyük önem taşımaktadır. Literatürde çene bölgesinde oluşan kemik ve doku hasarlarının iyileşme sürelerinin kısaltılmasında elektromanyatik alan kullanımı üzerine yapılmış çalışmalar mevcuttur. $\mathrm{Bu}$ çalışmalarda temel olarak uygun antenler aracılığıyla doku bölgesi elektromanyetik alana maruz birakılarak doku bölgesindeki yaralanmaların tedavi edilmektedir (Al-Mandeel vd., 2008). Federal İletişim Kurumu (Federal Communications Commission, FCC) $40.68 \mathrm{MHz}, 13.56 \mathrm{MHz}$ ve $27.12 \mathrm{MHz}$ frekanslarını klinik koşullarda doku yara tedavisinde kullanılmak üzere tahsis etmiştir (Foley vd., 1990). Literatürde yapılan doku yara tedavileri çalışmalarında genellikle $27 \mathrm{MHz}$ frekanslı spiral veya helmholtz bobin antenler kullanılmıştır (Guo vd., 2011).

Diş ve çene cerrahisinde gömülü düş çekimleri, sinüs yükseltme, implant tedavisi, distraksiyon osteogenezisi, ortognatik cerrahi, çene nekroz tedavisi gibi operasyonlar sonrasında doku bölgesinde oluşan yaraların iyileşme sürelerini hızlandırılmak komplikasyonları önlemek, hastanın normal hayata dönüş süresini kısaltmak, tedavi başarı oranını arttırmak, enfeksiyon riskini azaltmak, başarısızlık nedeni ile doğacak ek tedavi masraflarının önüne geçmek büyük önem taşımaktadır. Literatürde yapılan çalışmalar incelendiğinde başarılı sonuçlar alınan çalışmaların yanı sıra elektromanyetik alan tedavisinin doku ve kemik iyileşmesi üzerine tek başına yeterli olmadığ ancak ek bir tedavi şeklinde uygulanabileceği yönünde çalışmalarda mevcuttur. Mandibula kırıklarının tedavisinde yapılan bir çalışmada darbeli elektromanyetik alan uygulamasının kemik yoğunluğunda artış meydana getirdiği belirlenmiştir (Refai vd., 2013). Mandibula kırıklarında darbeli elektromanyetik alan uygulamasının kırık iyileşmesinde yararlı bir etki gösterdiği belirtilmiştir (Abdelrahim vd., 2011). Ağız bölümünün dışına konumlandırılan darbeli elektromanyetik alan cihazının, doku bölgesinde oluşan yara ve ağrı tedavisinde etkili olduğu belirtilmiştir (Stocchero vd., 2015). Diş hekimliğinde yapılan operasyonlar sonrasında darbeli elektromanyetik alan uygulamasının ağrı ve iltihaplanma üzerine iyileşme sağladığ ayrıca ve preoperatif uygulandığında ağrı üzerinde etkisinin arttığı belirtilmiştir (Aronofsky, 1971). Darbeli elektromanyetik alan uygulamasının oral cerrahi sonrası ağrı ve ödem tedavi süreçlerini kısalttığı belirtilmiştir (Rhodes, 1981). İmplant tedavisi sonrasında darbeli elektromanyetik alan uygulanan hastalarda, uygulanmayan gruplara göre daha hızlı kemik iyileşmesi olduğu belirtilmiştir. (Atay vd., 2003). Tavşanlarda uygulanan implant yerleştirilmesi sonrasında darbeli elektromanyetik alanın kemik osteoblastik aktivitesi ve yeni trabeküler kemik oluşumunu olumlu yönde etkilediği belirtilmiştir (Özen vd., 2004). Darbeli elektromanyetik alanın farelerdeki doku yaralarının iyileştirilmesi üzerine etkileri takip edilmiş ve 9 gün içinde anlamlı bir iyileşmenin olduğu gözlenmiştir (Athanasiou vd., 2007). Diyabetik farelerde oluşan yaraların tedavisi edilmesinde, darbeli elektromanyetik alan uygulanan farelerdeki yara iyileşme süresinin uygulanmayan farelere göre daha hızlı olduğu belirlenmiştir (Goudarzi vd., 2010). Belirli zaman aralıklarında uygulanan elektromanyetik alanın, kemik iyileşmesinde ve peri-implant kemik oluşumunda tedavi şekli olarak kullanılabileceği yönünde olumlu sonuçlar belirtilmiştir (Grana vd., 2008). Düşük frekanslı darbeli elektromanyetik alan tedavisinin kusurlu kemik oluşumndaki kök hücrelerin kalsiyum oranı ve hücre sayılarını arttırdığ 1 belirtilmiştir (Tsai vd., 2009). Elektromanyetik alan tedavilerinin gelişimi, tekniği, cihazlar ve geleceği konusunda yapılan çalışmalara yer verilmiştir (Markov, 2007). Darbeli elektromanyetik alanın implant ile kemik arasındaki formasyon sürecini hızlandırdırdığı ve tedavi başarı oranını arttırdığ belirtilmiştir (Barak vd., 2016). Düşük voltajlı elektrik sinyallerinin dokuda oluşan yaraların iyileşme sürelerinin hızlandırdığı belirtilmiştir (Weiss vd., 1990).

$\mathrm{Bu}$ çalışmada, CST programı kullanılarak insan çene dokusunda oluşan yaraları iyileştirmek amacı ile bir anten düzeneğinin tasarımı yapılmıştır. Anten düzeneği mikroşerit anten ile horn yansitıcı olmak üzere iki parçadan oluşmaktadır. Mikroşerit anten $27 \mathrm{MHz}$ frekansında çalışmakta olup horn yansıtıcı ile sadece çene bölgesine 1şıma yapılması sağlanmıştır. Anten düzeneği, insan kafa yapısında bulunan beyin, göz gibi hassas organlara etki etmeyecek ve çene bölgesinde uygun SAR değerlerinde olacak şekilde oluşturulmuştur.

\section{Materyal ve Metot}

Mikroşerit anten tasarımında genel olarak ilk aşamada çalışma frekansı $\left(f_{r}\right)$, elektriksel geçirgenlik katsayısı $\left(\varepsilon_{r}\right)$ ve dielektrik malzemenin yüksekliği (h) belirlenir. İkinci aşamada ise yama (patch) kısmın genişliği (W), yalıtkanın geçirgenlik katsayısının etkin değeri $\left(\varepsilon_{\text {eff }}\right)$, yama boyundaki saçaklanmaya bağlı değişim $(\Delta \mathrm{L})$ sırasıyla $(1),(2),(3)$ eşitliklerinde verildiği gibi hesaplanır (Balanis, 2005).

$$
\begin{gathered}
\mathrm{W}=\frac{\mathrm{c}}{2 \mathrm{f}_{\mathrm{r}}} \sqrt{\frac{2}{\varepsilon_{\mathrm{r}}+1}} \\
\varepsilon_{\text {eff }}=\frac{\varepsilon_{\mathrm{r}}+1}{2}+\frac{\varepsilon_{\mathrm{r}}-1}{2}\left[1+12 \frac{\mathrm{h}}{\mathrm{W}}\right]^{-\frac{1}{2}} \\
\Delta \mathrm{L}=0.412 \mathrm{~h} \frac{\left(\varepsilon_{\mathrm{eff}}+0.3\right)\left(\frac{\mathrm{W}}{\mathrm{h}}+0.264\right)}{\left(\varepsilon_{\mathrm{eff}}-0.258\right)\left(\frac{\mathrm{W}}{\mathrm{h}}+0.8\right)}
\end{gathered}
$$

Yamanın etkin uzunluğu (Leff) aşağıda verildiği gibi hesaplanır.

$$
\begin{aligned}
& \mathrm{L}_{\mathrm{eff}}=\mathrm{L}+2 \Delta \mathrm{L} \\
& \mathrm{L}_{\mathrm{eff}}=\frac{\mathrm{c}}{2 \mathrm{f}_{\mathrm{r}} \sqrt{\varepsilon_{\mathrm{eff}}}}
\end{aligned}
$$

Dikdörtgen mikroşerit yama kısmının üsten görünüşü ve üç boyutlu görünümü Şekil 1'de verilmiştir. Dielektrik tabakanın kalınlığı ile serbet uzaydaki dalga boyu $\left(\lambda_{0}\right)$ arasındaki ilişki (6) eşitliğinde verildiği gibidir (Balanis, 2005).

$$
0.003 \lambda_{0} \leq \mathrm{h} \leq 0.05 \lambda_{0}
$$

Dielektrik tabakanın genişliği ve uzunluğuna ait ifadeler (7) ve (8) verildiği gibidir (Balanis, 2005).

$$
\begin{gathered}
W_{s}=W+6 h \\
L_{s}=L+6 h
\end{gathered}
$$


Yama kolunun genişliği (9) eşitliğinde verildiği gibidir.

$$
\mathrm{W}_{\mathrm{m}}=\frac{7.48 \mathrm{~h}}{\mathrm{e}^{\left(\mathrm{z}_{0} \frac{\sqrt{\varepsilon_{\mathrm{r}}+1.41}}{87}\right)}}-1.25 \mathrm{t}
$$

Burada t iletken malzemenin (yama ve toprak) kalınlığını ifade etmektedir.

Yama kolunun uzunluğu (10) eşitliğindeki gibi hesaplanır.

$$
\mathrm{L}_{\mathrm{m}}=\left(\frac{\mathrm{c}}{\mathrm{f}}\right) /(4 \sqrt{\mathrm{K}})
$$

Burada $\mathrm{K}$ değeri (11) eşitliğinde verildiği gibidir.

$$
\mathrm{K}=\left(\frac{\varepsilon_{\mathrm{r}}+1}{2}\right)+\left(\left(\frac{\varepsilon_{\mathrm{r}}-1}{2}\right) \times\left(\frac{1}{\sqrt{\left(1+\left(\frac{\mathrm{h}}{\mathrm{w}_{\mathrm{t}}}\right)\right)}}\right)\right)
$$

Burada;

$$
\begin{aligned}
& G=\sqrt{4500\left(\varepsilon_{r}\right)^{2}\left(\frac{L}{W}\right)^{2} /\left(\varepsilon_{r}-1\right)}, \quad a_{3}=e^{\left(G \sqrt{\varepsilon_{r}} / 60\right)}, p=4 h a_{3}, \\
& q=32 h^{2}, \quad W_{t}=-\left(\frac{p}{2}\right)-\sqrt{\left(\left(\frac{p}{2}\right)^{2}-q\right)}
\end{aligned}
$$
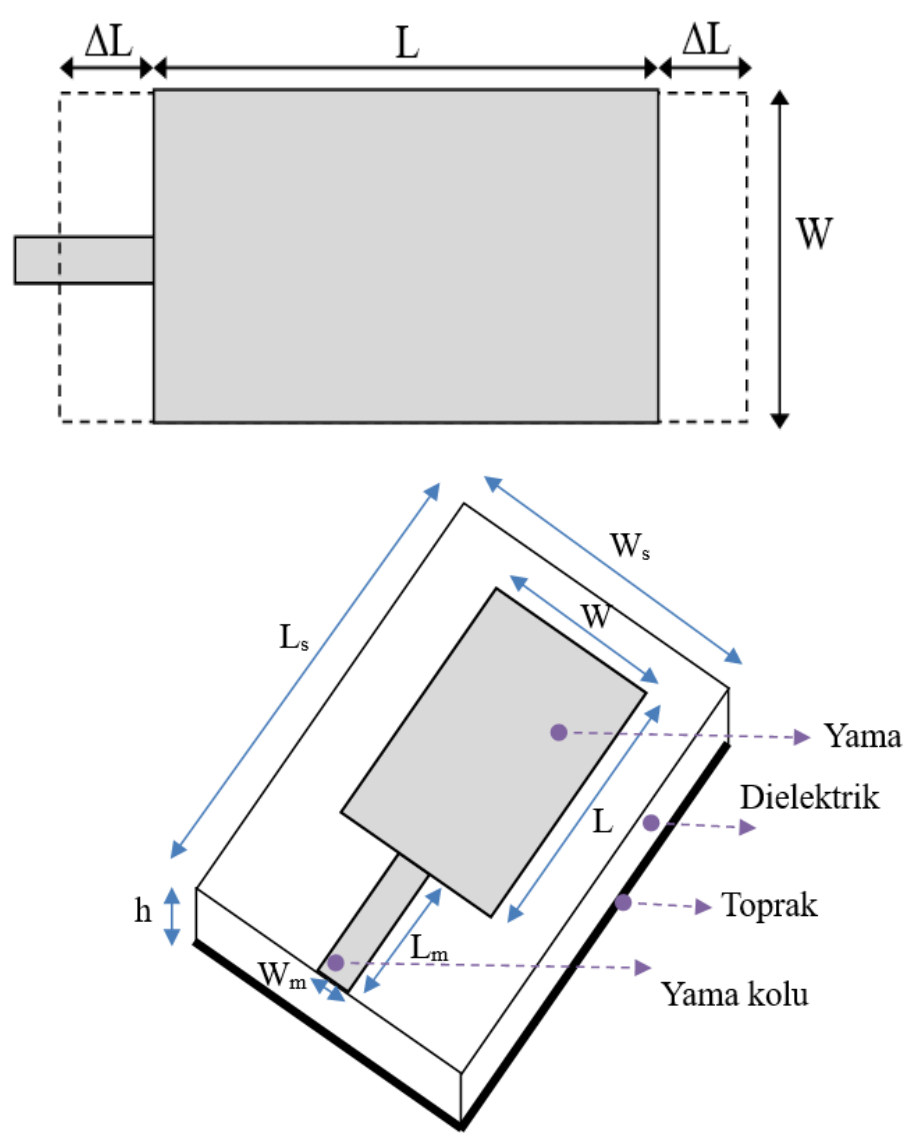

Şekil 1. Antenin yama kısmının üstten ve üç boyutlu görünümü

Yansıma katsayı (reflection coefficient, $\mathrm{S}_{11}$ ) antenin çalışma frekans aralığının belirtilmesi için kullanılan temel parametre olup (12) eşitliğinde verildiği gibi hesaplanır.

$$
\Gamma=\mathrm{S}_{11}=\frac{\mathrm{Z}_{\mathrm{L}}-\mathrm{Z}_{0}}{\mathrm{Z}_{\mathrm{L}}+\mathrm{Z}_{0}}
$$

Burada $\mathrm{Z}_{\mathrm{L}}$ yük direncini, $\mathrm{Z}_{0}$ ise antenin karakteristik empesansını göstermektedir.

Şekil 2'de tasarlanan mikroşerit anten yapısı verilmiştir. Mikroşerit anten tasarımında, mikroşerit anten ölçülerinin belirlenmesinde kullanılan formüller ile beraber yama (patch), dielektrik (substrate) ve toprak (ground) kısımlarının geometrileri düzenenerek anten boyutları küçültülmüştür. Tasarımı yapılan mikroşerit antenin toprak tabakası $0.5 \mathrm{~mm}$ kalınlığında bakır malzeme, dielektrik tabakası $0.5 \mathrm{~mm}$ kalınlığında FR-4 malzeme ve yama dairesi $1 \mathrm{~mm}$ kalınlığında bakır malzemedir. Tasarlanan mikroşerit antenin ebatları Şekil 2.c'de detaylı şekilde verilmiştir.

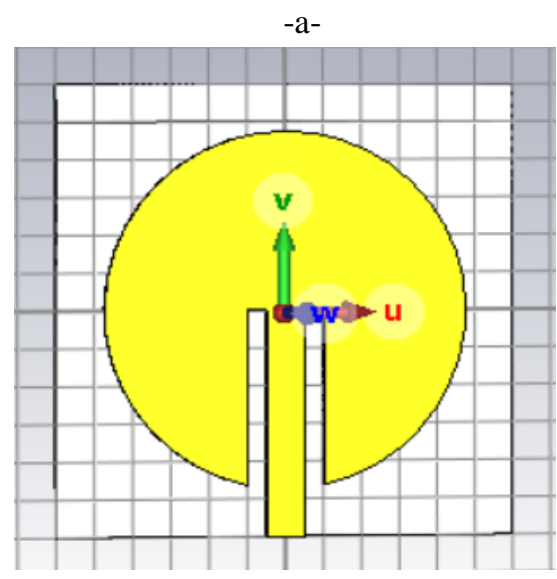

$-b-$
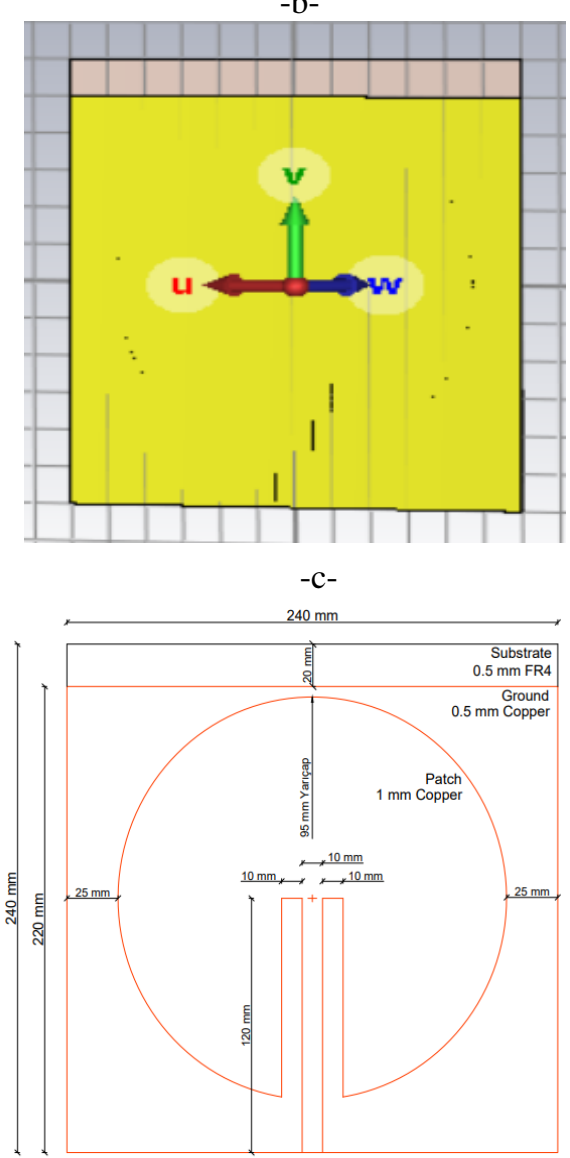

Şekil 2. Tasarlanan mikroşerit antenin a) önden, b) arkadan görünüşü, c) ebatlarl 
Mikroşerit antenin üzerine uygun frekans değerinin sağlanması ve lokal bir bölgeye 1şıma yapması amacıyla horn yansıtıcı ilave edilmiştir. Horn yansıtıcı $0.5 \mathrm{~mm}$ kalınlığında 200 $\mathrm{mm}$ uzunluğunda çelik malzemeden oluşmakta olup taban ebatları $220 \mathrm{~mm}$ x $220 \mathrm{~mm}$, üst kare ebatları $20 \mathrm{~mm}$ x 20 mm'dir. Mikroşerit horn yansıtıcı yapısı ve ebatları Şekil 3'de verilmiştir.
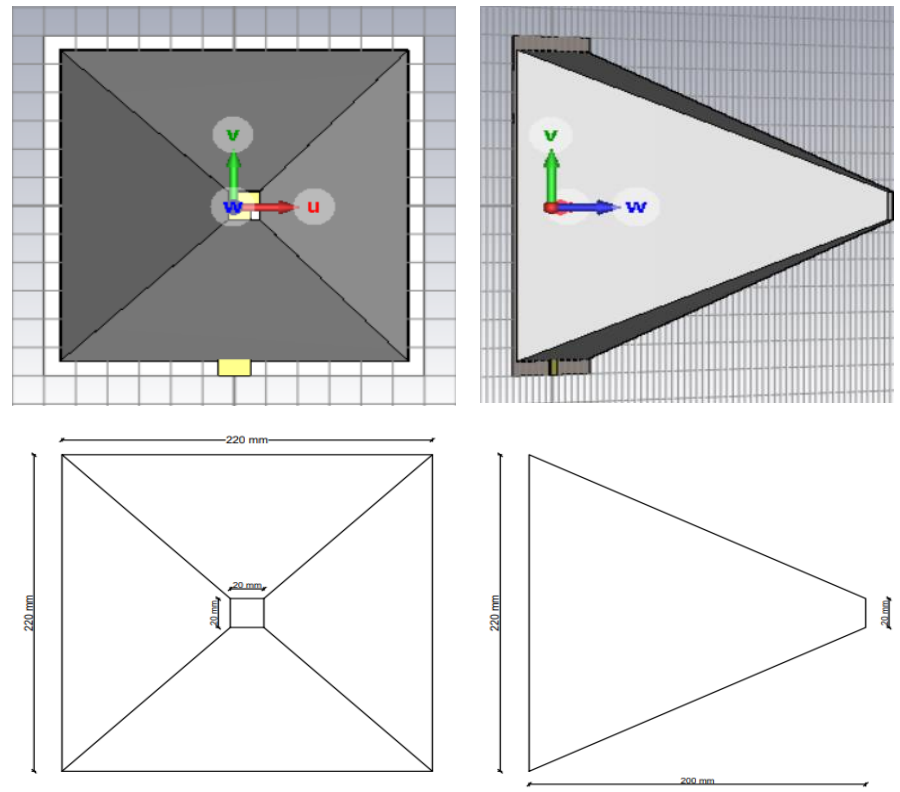

Şekil 3. Tasarlanan horn yansitıcı ve ebatları

\section{Araştırma Sonuçları ve Tartışma}

CST programı kullanılarak tasarımı yapılan mikroşerit antenin horn yansitıc1 yapısı varken ve yokken ki yansıma katsayısı $\left(\mathrm{S}_{11}\right)$ farklılık göstermektedir. Horn yansitıcı yokken (Şekil 4.a) mikroşerit antenin $27 \mathrm{MHz}$ frekansında $\mathrm{S}_{11}$ değeri $-7.67 \mathrm{~dB}$ iken bu değer horn yansitıcı varken (Şekil 4.b) -11.4 dB'dir.

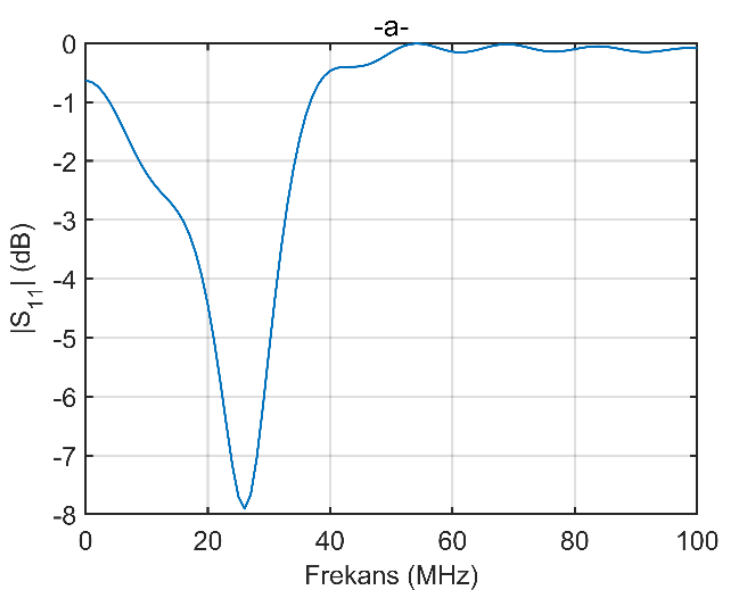

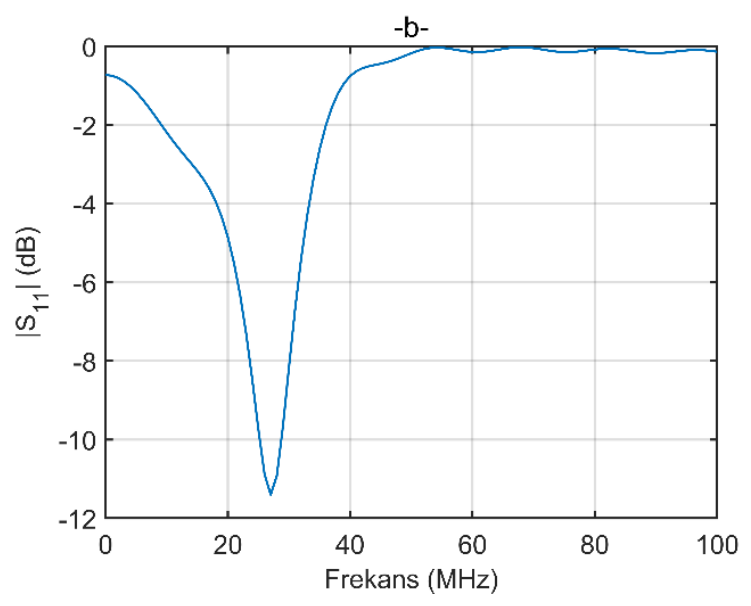

Şekil 4. Horn yansitıcı yüzey a) yokken, b) varken antenin $S_{11}$ değeri

CST'de yapılan benzetimlerde antene $50 \mathrm{~W}$ güç verildiğinde antenden $0.51 \mathrm{~V} / \mathrm{m}$ elektrik alan (E), $0.001 \mathrm{~A} / \mathrm{m}$ manyetik alan (H) değeri elde edilmiştir. CST' de yapılan benzetim sonucunda elde edilen elektrik alan ve manyetik alan üç boyutlu görselleri Şekil 5'de verilmiştir.
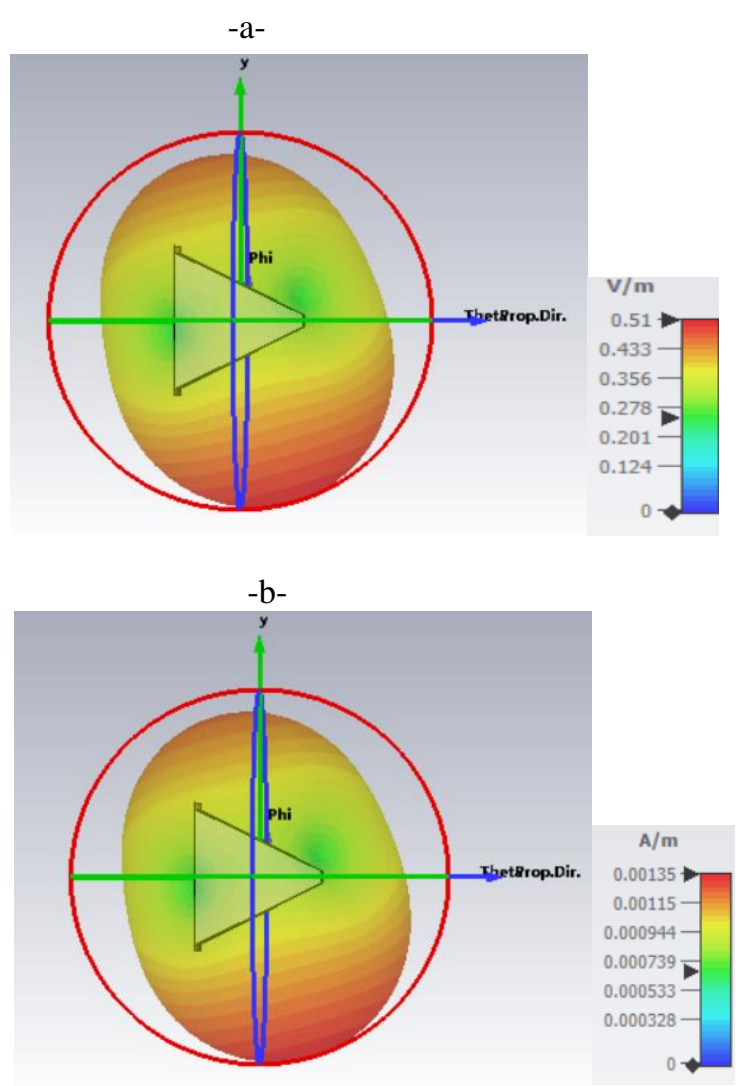

Şekil 5. Anten düzeneğine ait a) elektrik alan, b) manyetik alan değişimi 
Tasarlanan antenin bir boyutlu 1şıma grafikleri Şekil 6'da verilmiştir.

$-a-$

Farfield E-Field $(r=1 \mathrm{~m})$ Abs (Theta $=90$ )

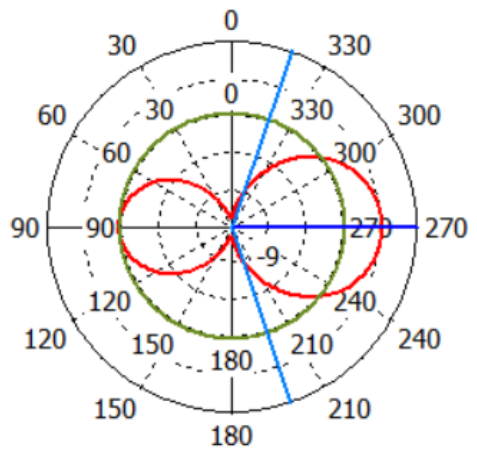

Phi / Degree vs. dB(V/m)

$-b-$

Farfield H-Field $(\mathrm{r}=1 \mathrm{~m})$ Abs (Theta $=90)$

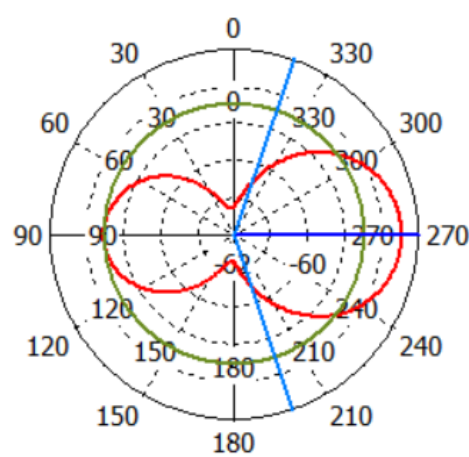

Phi / Degree vs. $\mathrm{dB}(\mathrm{A} / \mathrm{m})$

Şekil 6. Anten düzeneğinin bir boyutlu a) elektrik alan, b) manyetik alan ışıma diyagramı

Mikroşerit anten ile CST'de yer alan insan kafa modeli üzerinden yapılan benzetim sonuçları Şekil 7'de verilmiştir. Antenin yaptığ 1 1şıma insan kafa modelinin sağ tarafinda yer alan bölümünün tamamını kaplamaktadır. $\mathrm{Bu}$ durum çene bölgesinde yer alan doku yaraları ile beraber beyin, göz gibi hassas organların da elektromanyetik alana maruz kalmasına sebep olmaktadır. Benzetim sonuçlarında $50 \mathrm{~W}$ anten giriş gücünde $0.148 \mathrm{~W} / \mathrm{kg}$ özgül soğurma oranı (Specific Absorption Rate, SAR) değeri elde edilmiştir.

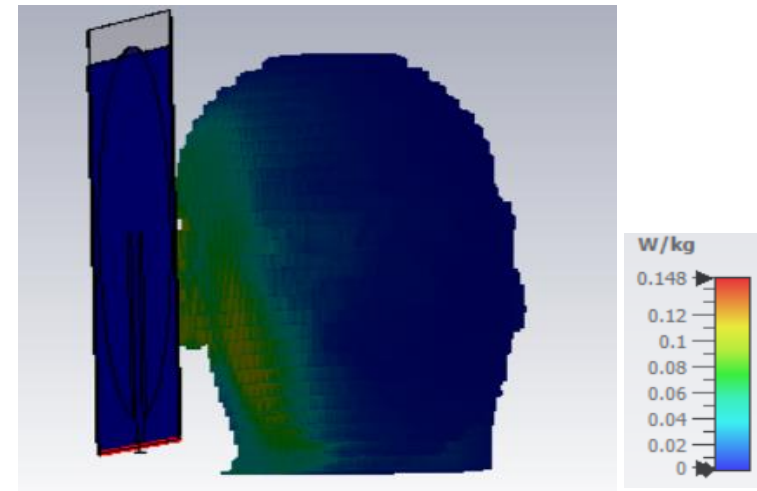

Şekil 7. Mikroşerit anten insan kafası benzetim sonuçları
Tasarlanan anten düzeneği CST programında yer alan insan kafa modeli üzerinden anten giriş gücü $50 \mathrm{~W}$ değeri verilmiş ve sonuçlar Şekil 8'de gösterilmiştir. Yapılan benzetim sonucunda antenin sadece çene bölgeye ışıma yapması sağlanmıştır ve en yüksek $0.005 \mathrm{~W} / \mathrm{kg}$ SAR değeri elde edilmiştir. $\mathrm{Bu}$ değer ICNIRP tarafından belirlenen tüm vücut için $0.08 \mathrm{~W} / \mathrm{kg}$ ve $\mathrm{k} ı$ smi vücut bölgesi için $2 \mathrm{~W} / \mathrm{kg}$ limit değerinin çok altındadır.

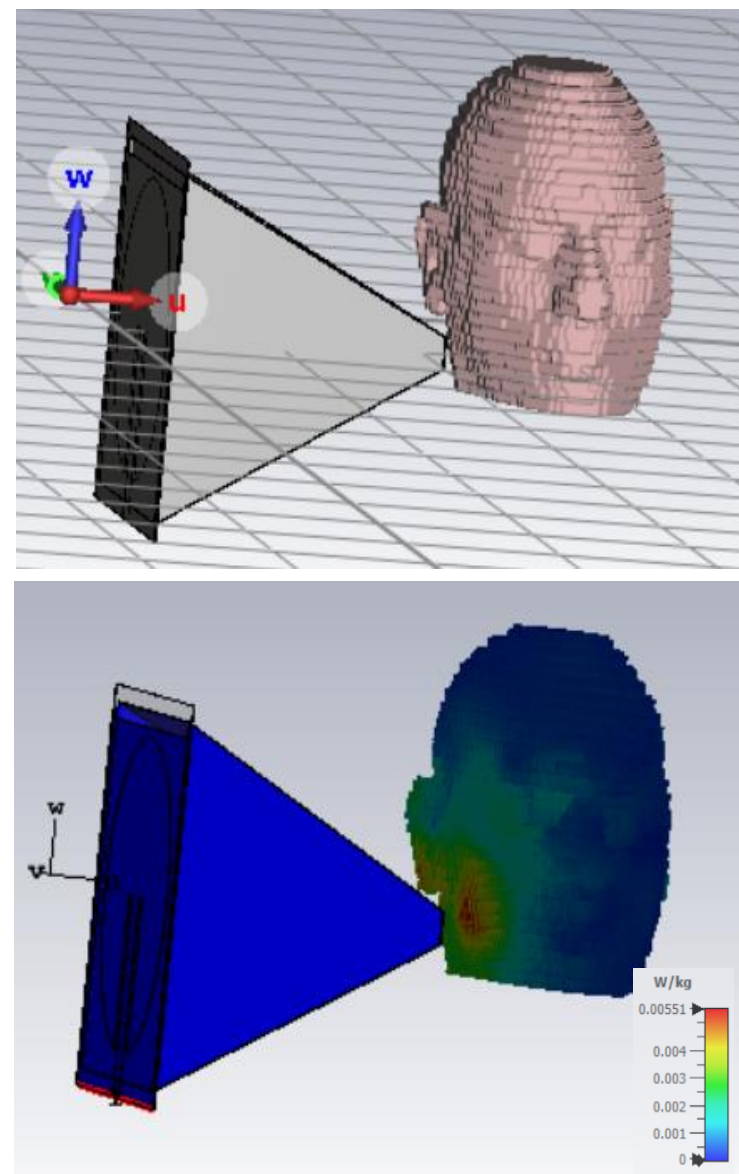

Şekil 8. Anten düzeneği ile CST insan kafa modeli benzetimi

\section{Sonuç}

$\mathrm{Bu}$ çalışmada çene cerrahisi operasyonları sonrası doku bölgesinde oluşan yaraların tedavi süresini azaltmak amacı ile 27 $\mathrm{MHz}$ frekans bandında çalışan bir anten düzeneği tasarlanmıştır. CST programı üzerinden alınan sonuçlar doğrultusunda $27 \mathrm{MHz}$ frekansında $-11.4 \mathrm{~dB} \mathrm{~S} \mathrm{~S}_{11}$ değeri elde edilmiştir. Tasarlanan anten, horn yansitıcısı ile istenilen bölgeye ve daha lokal bir alana 1şıma yapabilme imkanına sahiptir. Böylece vücudun diğer organlarının bu ışımadan etkilenmelerinin önüne geçilebilmektedir. Benzetim sonucunda antene $50 \mathrm{~W}$ güç verildiğinde antenden $0.51 \mathrm{~V} / \mathrm{m}$ elektrik alan, $0.001 \mathrm{~A} / \mathrm{m}$ manyetik alan değeri elde edilmiştir. CST insan modeli üzerinden yapılan benzetim sonucunda ise $50 \mathrm{~W}$ gücünde 0.005 W/kg SAR değeri elde edilmiştir. Literatürde yapılan çalışmalar incelendiğinde doku yara tedavisi için belirli bir elektrik alan veya manyetik alan değeri belirlenmemiştir. $\mathrm{Bu}$ sebeple tasarlanan antenin giriş gücü arttırılarak veya azaltılarak istenilen elektrik alan ve manyetik alan değerleri elde edilebilir. $\mathrm{Bu}$ çalışma ve sonuçları elektromanyetik alan tedavilerinin doku bölgesinde oluşan yaraların tedavi edilmesi yönünde yapılacak çalışmalara 1 şı tutacaktır. 


\section{Kaynakça}

Abdelrahim A., Hassanein H.R., Dahama M., (2011). Effect of pulsed electromagnetic field on healing of mandibular fracture: a preliminary clinical study. J Maxillofac Oral Surg 69(6): 1708-1717.

Al-Mandeel M. M., Watson, T. (2008). Pulsed and continuous shortwave therapy. In: Watson, T. Editor, Electrotherapy: Evidence-Based Practice (pp. 137-160), 12th edition, Edinburgh, New York: Churchill Livingstone.

Aronofsky D.H. (1971). Reduction of dental postsurgical symptoms using nonthermal pulsed high-peak-power electromagnetic energy. Oral Surg Oral Med Oral Pathol, 32(5):688-696.

Atay A, Özen J, Oruç S, Dalkız M, Beydemir B, Halaç E. (2003). Diş hekimliğinde implant çevresindeki kemik iyileşmesinin hılandırılmasında kullanılabilecek elektromanyetik alan darbe üreteci tasarımı. Gülhane Tıp Dergisi 45(4): 350- 354.

Athanasiou A., Karkambounas, S., Batistatou, A., Lykoudis, E., Katsaraki, A., Kartsiouni, T., et al., (2007). The effect of pulsed electromagnetic fields on secondary skin wound healing: an experimental study. Bioelectromagnetics, 28(5):362-368.

Balanis C.A., (2005). Antenna Theory: Analysis and Design: Willey-Inter Science.

Barak S, Neuman M, Iezzi G, Piattelli A, Perrotti V, Gabet Y. (2016). A new device for improving dental implants anchorage: a histological and micro-computed tomography study in the rabbit. Clin Oral Implants 27(8): 935-942.

Foley N.D., Barry C., Coughlan R.J., O'Connor P., Roden D. (1990). Pulsed high frequency $(27 \mathrm{MHz})$ electromagnetic therapy for persistent neck pain. A double blind, placebocontrolled study of 20 patients. Orthopedics, 13(4):445-451.

Goudarzi I., Hajizadeh, S., Salmani, M. E., Abrari, K. (2010). Pulsed electromagnetic fields accelerate wound healing in the skin of diabetic rats. Bioelectromagnetics, 31(4):318323.

Grana D.R, Marcos H, Kokubu G.A. (2008). Pulsed electromagnetic fields as adjuvant therapy in bone healing and peri-implant bone formation: an experimental study in rats. Acta Odontol Latinoam 21(1): 77-83.

Guo L., Kubat N.J., Isenberg R.A. (2011). Pulsed radio frequency energy (PRFE) use in human medical applications. Electromagnetic Biology and Medicine, 30(1): 21-45.

Markov M. S., (2007). Pulsed electromagnetic field therapy history, state of the art and future. The Environmentalist, 27: 465-475

Özen J, Atay A, Oruç S, Dalkız M, Beydemir B, Develi S. (2004). Evaluation of pulsed electromagnetic fields on bone healing after implant placement in the rabbit mandibular model. Turk J Med 34(2): 91-95.

Refai H., Radwan D., Hassanien N. (2014). Radiodensitometric Assessment of the Effect of Pulsed Electromagnetic Field Stimulation Versus Low Intensity Laser Irradiation on e-ISSN: 2148-2683
Mandibular Fracture Repair: A Preliminary Clinical Trial. J Maxillofac Oral Surg 13(4): 51-457.

Rhodes L, (1981). The adjunctive utilization of diapulse therapy (pulsed high peak power lectromagnetic energy) in accelerating tissue healing in oral surgery. Nat Dent Assoc Quarterly 39(1): 166-175.

Stocchero M, Gobbato L, De Biagi M, Bressan E, Sivolella S. (2015). Pulsed electromagnetic fields for postoperative pain: a randomized controlled clinical trial in patients undergoing mandibular third molar extraction. Oral Surg Oral Med Oral Pathol Oral Radiol, 119(3):293-300.

Tsai M. T., Li, W. J., Tuan, R.S., Chang, W. H. (2009). Modulation of osteogenesis in human mesenchymal stem cells by specific pulsed electromagnetic field stimulation. Journal of Orthopaedic Research, 27(9):1169-1174

Weiss D. S., Kirsner, R., Eaglstein, W. H. (1990). Electrical stimulation and wound healing. Archives of dermatology, 126(2):222-225. 